Article

\title{
Design of a Monopulse System Using a Single Patch Radiator with a Simple Multi-Mode Substrate Integrated Waveguide Feeding Network
}

\author{
Sangwoon Youn ${ }^{1}$, Tae Heung Lim ${ }^{1}$, Byung-jun Jang ${ }^{2}$ and Hosung Choo ${ }^{1, * \mathbb{D}}$ \\ 1 School of Electronic and Electrical Engineering, Hongik University, Seoul 04066, Korea; \\ tirano88@mail.hongik.ac.kr (S.Y.); qpzm0105@mail.hongik.ac.kr (T.H.L.) \\ 2 School of Electronic and Electrical Engineering, Kookmin University, Seoul 04066, Korea; \\ bjjang@kookmin.ac.kr \\ * Correspondence: hschoo@hongik.ac.kr
}

Received: 26 September 2020; Accepted: 14 October 2020; Published: 16 October 2020

\begin{abstract}
This paper proposes the design of a single radiator monopulse antenna with a substrate integrated waveguide (SIW) multi-mode feeding system to reduce the aperture size and simplify the feeding structure. The proposed antenna can effectively reduce the overall system size by using a single patch radiator, compared to conventional systems that require multiple radiators. In addition, to simplify the structure of the pattern comparator we use a SIW multi-mode feeding system with $\mathrm{TE}_{10}$ and $\mathrm{TE}_{20}$ modes. To verify the feasibility, the patch antenna with the SIW multi-mode feed is fabricated, and its antenna characteristics of reflection coefficients, mutual coupling, and radiation patterns are measured in a full anechoic chamber. The accuracy of the direction of arrival (DOA) estimation is further improved by applying the derived calibration factor to the resulting sum and difference ratio. The results demonstrate that the proposed antenna is suitable for compact and lightweight monopulse systems with the single radiator and the simple multi-mode feeding network.
\end{abstract}

Keywords: single radiator multi-ports; SIW feeding network; monopulse antenna; multi-mode antenna

\section{Introduction}

Monopulse systems have been widely used for target tracking in various military purposes such as missile seeker, a shipborne satellite communication (SATCOM) station, an airborne-based sense and avoid (ABSAA) and satellite tracking [1-5]. In such applications, the monopulse systems typically detect the direction of targets using the amplitude ratio of the sum and difference channels of the received signals [6,7]. Therefore, these systems should consist of multiple antenna elements and a feeding network with a channel comparator. Horn antennas connected by metallic waveguide feeding networks are traditionally used for monopulse radiators and comparators to achieve stable system characteristics and a durable structure [8,9]. However, horn-based monopulse systems have significant disadvantages as a result of their bulky structure sizes, complicated feeding networks, and high manufacturing costs. To overcome these problems, bulky radiators and waveguide feeding networks can be replaced by planar microstrip patches and substrate integrated waveguide (SIW) feeding networks, which can provide lightweight and low-profile structures [10-14]. For radiators, various antenna types have been investigated, including microstrip patches, Yagi-Uda geometry, and slotted antennas [15-20]. Comparators have also been extensively studied by employing microstrip couplers and magic tee comparators in monopulse systems [21-25]. While these techniques have allowed us to reduce the size of the monopulse system to some extent, the monopulse array antenna still requires a large aperture size due to the use of multiple radiators and the sophisticated design of the monopulse comparators. 
In this paper, we propose a novel design structure of the monopulse antenna system that can operate with only a single radiator to reduce the aperture size, where the complicated waveguide comparator is also replaced by the simple planar SIW multi-mode feeding network that can obtain the ratio of sum and difference patterns. The proposed antenna consists of a single rectangular patch printed on a dielectric substrate, which is connected to a two-port SIW feeding network. The two ports in the SIW feeding network transmit transverse electric $(\mathrm{TE})_{10}$ and $\mathrm{TE}_{20}$ modes to the single patch antenna, respectively, resulting in the sum and difference radiation patterns. The direction of arrival (DOA) is then estimated by the amplitude ratio of the sum to difference patterns. In this design procedure, the proposed monopulse array antenna is designed at the target frequency of $4.85 \mathrm{GHz}$ in order to demonstrate the capability of the commercial Industry-Science-Medical (ISM) band applications such as internet of things (IoT), unmanned aerial vehicles (UAVs), and mobile devices [26,27], although the conventional monopulse system is usually utilized in the military application. To verify the feasibility, the single patch antenna with the dual-mode SIW feeding system is fabricated, and its antenna characteristics such as the reflection coefficient, mutual coupling, and radiation patterns are measured in a full anechoic chamber. To better understand the operating principle of the antenna, we observe near-field distributions, the sum and difference radiation patterns, and impedance matching characteristics in accordance with some important design parameters. The accuracy of the DOA estimation is further improved by applying the derived calibration factor to the resulting sum and difference ratio. The results demonstrate that the proposed antenna, with its single radiator and simple multi-mode feeding network, is suitable for compact and lightweight monopulse systems.

\section{Proposed Antenna with SIW Feeding Network}

A conventional pulsed radar system usually excites a pulse to measure a spatial distance or direction of a target using the elapsed time for receiving the reflected signal. For the range detection, the pulse width and period are important parameters for the range resolution of the radar system. The antennas in such radar systems require specific operating frequency bandwidths in terms of the radar applications due to the range resolution $[28,29]$. For the angle detection, the amplitude comparison is one of well-known methods that can find the direction of the target using the ratio of the difference/sum patterns. Thus, according to the applications, the antennas need adequate difference/sum radiation pattern beam widths and density of pattern measurement points, which can decide the angle resolution and the angle detection range [30,31]. From this background, we design the monopulse antenna system considering the difference/sum patterns for the spatial angle detection range and resolution.

Figure 1 shows the geometry of the proposed monopulse antenna using a single patch radiator with a simple multi-mode SIW feeder. The antenna structure is divided into three subsections of a microstrip patch, a $\mathrm{TE}_{10}$ mode SIW, and a $\mathrm{TE}_{20}$ mode SIW. All three parts are printed on thin FR4-substrates $\left(\varepsilon_{r}=3.8, \tan \delta=0.018\right)$ with thicknesses of $h_{1}$ and $h_{2}$. Figure 2 depicts the flow chart of a design methodology for the proposed antenna. First, the radiating patch is placed on the substrate with a width of $p_{1}$, and the patch width is adjusted by the parameter $p_{2}$. Second, we design the multi-mode feeding network consisting of two SIWs with different modes, which are excited by the microstrip lines. The two SIW feeders are spaced apart by a gap of $g$, and they have a low profile with a simple structure for fabrication compared to conventional complicated waveguide comparators. The SIW in Figure $1 \mathrm{~d}$ has a width of $w_{1}$ and a length of $l_{f 1}$. Via holes with a diameter of $d_{1}$ are arranged by a separation distance of $s_{1}$ to generate the $\mathrm{TE}_{10}$ mode that results in the sum pattern. These essential SIW parameters are determined using a conventional SIW equation in [32]. The SIW is then connected to a subminiature version A (SMA) connector through the microstrip line with a length of $l_{u 1}$ and a width of $w_{u 1}$ to excite the $\mathrm{TE}_{10}$ mode at $4.85 \mathrm{GHz}$. Similarly, the SIW for the $\mathrm{TE}_{20}$ in Figure $1 \mathrm{e}$ has the design parameters of $w_{2}, l_{f 2}, d_{2}$, and $s_{2}$. However, different from Figure $1 \mathrm{~d}$, a microstrip line $\left(w_{b}, l_{b}\right.$, $l_{u 2}$, and $\left.w_{u 2}\right)$, along with a slot $\left(l_{s 1}, l_{s 2}, w_{s 1}\right.$, and $\left.w_{s 2}\right)$, is used to effectively generate the $\mathrm{TE}_{20}$ mode at the same frequency, where the triangular slot is designed to obtain the impedance matching using 
microstrip to slot feeding transition technique [33-35]. Note that the SIWs have physically larger sizes than the patch radiator, since the patch radiator is excited through the rectangular coupling aperture constructed by the cross section of the SIW and the bottom of the substrate. It is because that the electric fields inside the substrate of the rectangular patch antenna need to be distributed with $\mathrm{TM}_{\mathrm{mn}}$ mode based on the cavity model [36-38]. Then, all sections are combined by vertically inserting the SIW feeding parts into the patch antenna. For detailed tuning, all parameters are optimized using a genetic algorithm (GA), and the best result is chosen from the final generation to fabricate the proposed structure. The detailed design parameters are listed in Table 1.

(a)

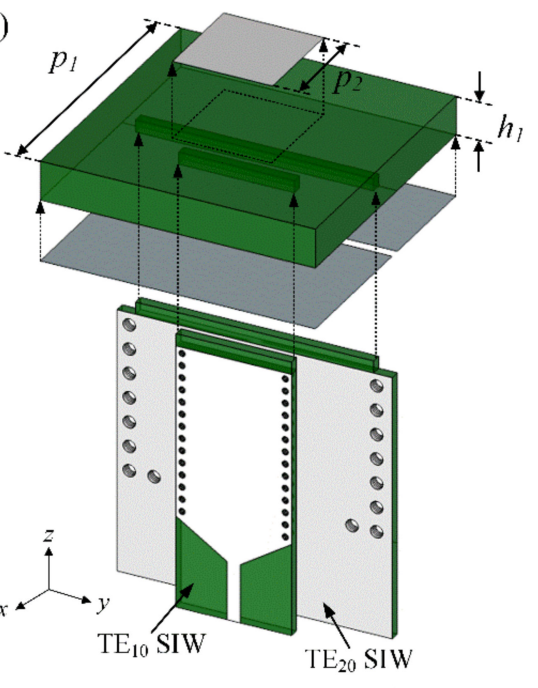

(b)

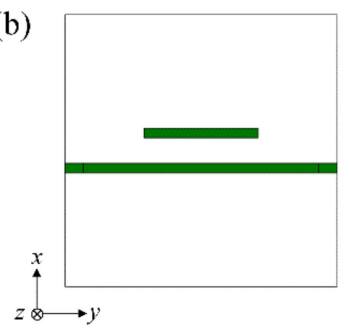

(c)

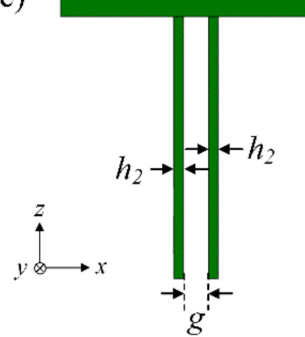

(d)

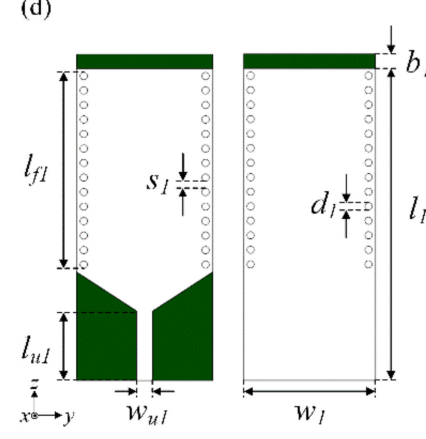

(e)

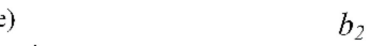

$b_{2}$

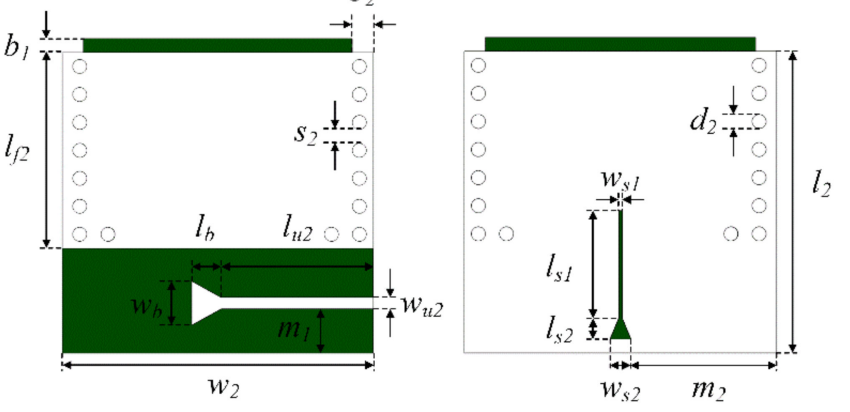

Figure 1. Design approach and geometry of the proposed antenna: (a) isometric view of the proposed antenna; (b) bottom view of the patch antenna; (c) side view of the proposed antenna; (d) top and bottom views of the substrate integrated waveguide (SIW) feeder for TE 10 mode; (e) top and bottom views of the SIW feeder for $\mathrm{TE}_{20}$ mode.

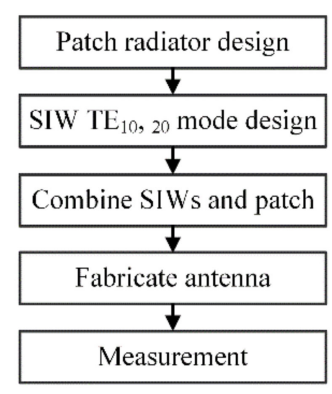

Figure 2. Design methodology of the proposed antenna. 
Table 1. Design parameters of the proposed antenna.

\begin{tabular}{cccc}
\hline Parameters & Values & Parameters & Values \\
\hline$p_{1}$ & $44.5 \mathrm{~mm}$ & $s_{1}$ & $1 \mathrm{~mm}$ \\
$P_{2}$ & $12.6 \mathrm{~mm}$ & $s_{2}$ & $2 \mathrm{~mm}$ \\
$h_{1}$ & $6.4 \mathrm{~mm}$ & $l_{f 1}$ & $28 \mathrm{~mm}$ \\
$h_{2}$ & $1.6 \mathrm{~mm}$ & $l_{f 2}$ & $28 \mathrm{~mm}$ \\
$g$ & $4.1 \mathrm{~mm}$ & $l_{u 1}$ & $8 \mathrm{~mm}$ \\
$w_{1}$ & $18.7 \mathrm{~mm}$ & $l_{u 2}$ & $21.8 \mathrm{~mm}$ \\
$w_{2}$ & $44.5 \mathrm{~mm}$ & $w_{b}$ & $6.3 \mathrm{~mm}$ \\
$l_{1}$ & $43 \mathrm{~mm}$ & $l_{b}$ & $4.2 \mathrm{~mm}$ \\
$l_{2}$ & $43 \mathrm{~mm}$ & $m_{1}$ & $4.55 \mathrm{~mm}$ \\
$w_{u 1}$ & $m_{2}$ & $20.75 \mathrm{~mm}$ \\
$w_{u 2}$ & $4.4 \mathrm{~mm}$ & $l_{s 1}$ & $15.3 \mathrm{~mm}$ \\
$d_{1}$ & $3.2 \mathrm{~mm}$ & $l_{s 2}$ & $3 \mathrm{~mm}$ \\
$d_{2}$ & $1 \mathrm{~mm}$ & $w_{s 1}$ & $0.5 \mathrm{~mm}$ \\
$b_{1}$ & $2 \mathrm{~mm}$ & $b_{2}$ & $2 \mathrm{~mm}$ \\
\hline
\end{tabular}

Figure 3 presents photographs of the fabricated antenna, in which all three parts are combined. Each part is designed to be assembled like a separate block so that they can generate each sum and difference pattern through the single rectangular radiator simultaneously. The microstrip lines, baluns, and patch radiator of the proposed antenna are fabricated by etching the metallic surface on the FR4-substrate, while the SIW is implemented by drilling a number of holes in the substrate and applying metal paint on the perforated surface.



(a)

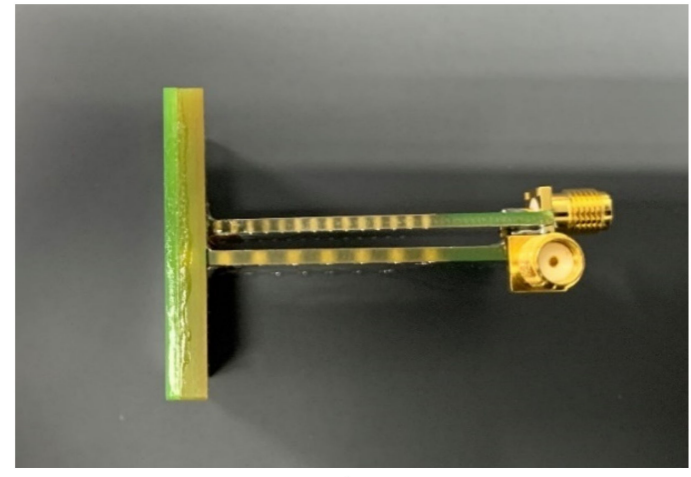

(b)

Figure 3. Photographs of the fabricated antenna: (a) isometric view; (b) side view.

Figure 4 presents a comparison of the measured and simulated reflection coefficients of the SIW for both the $\mathrm{TE}_{10}$ and $\mathrm{TE}_{20}$ modes. For the $\mathrm{TE}_{10}$ mode, the measurement of $-18.8 \mathrm{~dB}$ agrees well with the simulation of $-15.8 \mathrm{~dB}$ at $4.85 \mathrm{GHz}$, as shown in Figure $4 \mathrm{a}$. Figure $4 \mathrm{~b}$ again shows the reflection coefficients of the SIW for the $\mathrm{TE}_{20}$ mode, where the measurement and simulation are $-11.5 \mathrm{~dB}$ and $-16.6 \mathrm{~dB}$, respectively, at the same frequency of $4.85 \mathrm{GHz}$. Figure 5 shows the measured mutual coupling in comparison with the simulated data as a function of frequency. Measured and simulated mutual couplings are $-37.8 \mathrm{~dB}$ and $-34.9 \mathrm{~dB}$ at $4.85 \mathrm{GHz}$, respectively, and they are maintained below $-30 \mathrm{~dB}$ from $4.5 \mathrm{GHz}$ to $5.5 \mathrm{GHz}$. From these results, it can be seen that even with a single radiator, the patterns of each mode are well generated without significantly affecting each other. Figure 6 shows measured and simulated radiation efficiencies of the proposed antenna. The measured efficiencies of $\mathrm{TE}_{10}$ and $\mathrm{TE}_{20}$ modes were $38 \%$ and $29 \%$ at the target frequency of $4.85 \mathrm{GHz}$. There is an efficiency reduction due to conduction and dielectric losses. For example, when the $\mathrm{TE}_{10}$ mode is excited by the total available power of $1 \mathrm{~W}$, the resulting total power loss is $0.62 \mathrm{~W}$ (efficiency $=38 \%$ ). Over this total loss, the dielectric and conduction losses are $0.59 \mathrm{~W}$ and $0.03 \mathrm{~W}$, where the dielectric loss is dominant. The detailed values of the losses and the efficiencies for each SIW mode are listed in Table 2. 
To improve the antenna radiation efficiency, we designed another model using a Duroid $5880\left(\varepsilon_{r}=2.2\right.$, $\tan \delta=0.0009$ ) substrate for a low loss material. The detailed parameters of the efficiency improved model are listed in Table 3. Figure 7 shows the simulated efficiency results for the Duroid and FR-4 designs, and the antenna efficiency can be increased up to $82 \%$ at $4.85 \mathrm{GHz}$ using the Duroid substrate compared to that of $38 \%$ for the FR- 4 substrate in the $\mathrm{TE}_{10}$ mode.

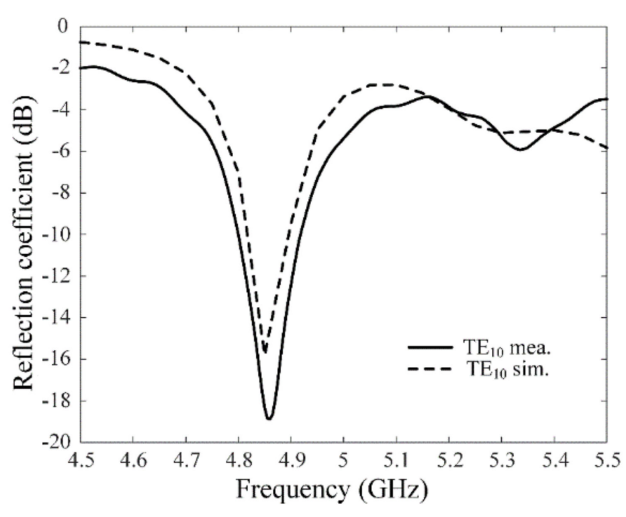

(a)

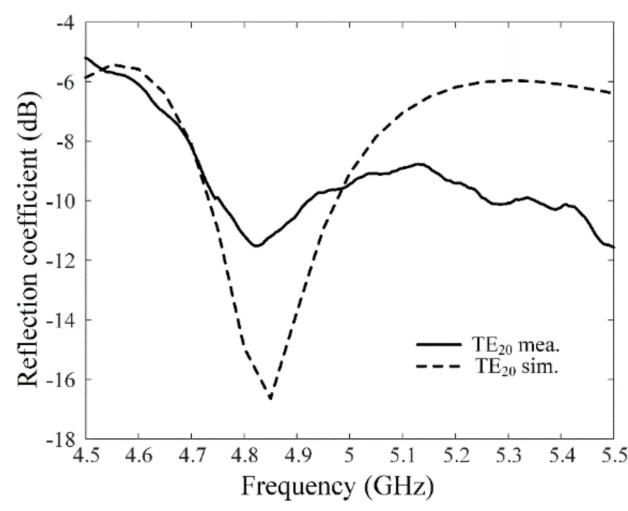

(b)

Figure 4. Simulated and measured reflection coefficients of the proposed antenna: (a) $\mathrm{TE}_{10}$ mode; (b) $\mathrm{TE}_{20}$ mode.

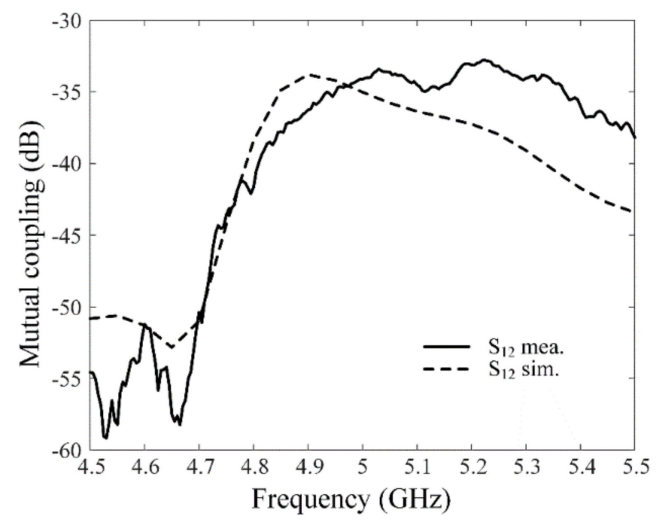

Figure 5. Simulated and measured mutual couplings of the proposed antenna.

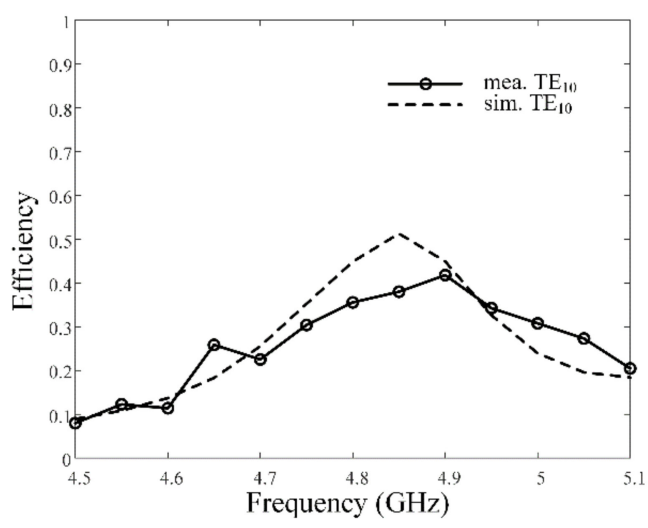

(a)

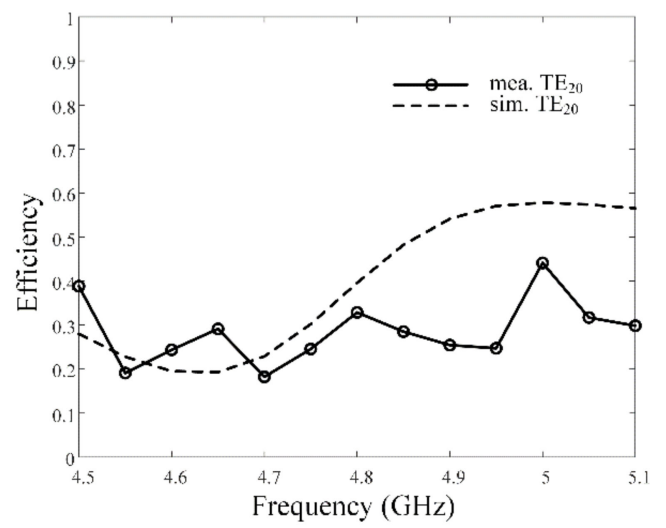

(b)

Figure 6. Simulated and measured efficiency of the proposed antenna: (a) $\mathrm{TE}_{10}$ mode; (b) $\mathrm{TE}_{20}$ mode. 
Table 2. Losses and efficiencies of the proposed antenna.

\begin{tabular}{ccccc}
\hline Port & Available Power & Dielectric Loss & Conduction Loss & Efficiency \\
\hline $\mathrm{TE}_{10}$ mode & $1 \mathrm{~W}$ & $0.59 \mathrm{~W}$ & $0.03 \mathrm{~W}$ & $38 \%$ \\
$\mathrm{TE}_{20}$ mode & $1 \mathrm{~W}$ & $0.675 \mathrm{~W}$ & $0.035 \mathrm{~W}$ & $29 \%$ \\
\hline
\end{tabular}

Table 3. Design parameters of the antenna using Duroid substrate.

\begin{tabular}{cccc}
\hline Parameters & Values & Parameters & Values \\
\hline$p_{1}$ & $62.8 \mathrm{~mm}$ & $s_{1}$ & $1.35 \mathrm{~mm}$ \\
$P_{2}$ & $20.25 \mathrm{~mm}$ & $s_{2}$ & $2.7 \mathrm{~mm}$ \\
$h_{1}$ & $8.64 \mathrm{~mm}$ & $l_{f 1}$ & $37.8 \mathrm{~mm}$ \\
$h_{2}$ & $2.16 \mathrm{~mm}$ & $l_{f 2}$ & $37.8 \mathrm{~mm}$ \\
$g$ & $5.5 \mathrm{~mm}$ & $l_{u 1}$ & $10.8 \mathrm{~mm}$ \\
$w_{1}$ & $25 \mathrm{~mm}$ & $l_{u 2}$ & $31.7 \mathrm{~mm}$ \\
$w_{2}$ & $62.8 \mathrm{~mm}$ & $w_{b}$ & $8.5 \mathrm{~mm}$ \\
$l_{1}$ & $58.05 \mathrm{~mm}$ & $l_{b}$ & $5.67 \mathrm{~mm}$ \\
$l_{2}$ & $58.05 \mathrm{~mm}$ & $m_{1}$ & $6.1 \mathrm{~mm}$ \\
$w_{u 1}$ & $m_{2}$ & $29.4 \mathrm{~mm}$ \\
$w_{u 2}$ & $5.94 \mathrm{~mm}$ & $l_{s 1}$ & $20.6 \mathrm{~mm}$ \\
$d_{1}$ & $4.32 \mathrm{~mm}$ & $l_{s 2}$ & $4.05 \mathrm{~mm}$ \\
$d_{2}$ & $1.35 \mathrm{~mm}$ & $w_{s 1}$ & $0.7 \mathrm{~mm}$ \\
$b_{1}$ & $2.7 \mathrm{~mm}$ & $b_{2}$ & $2 \mathrm{~mm}$ \\
\hline
\end{tabular}

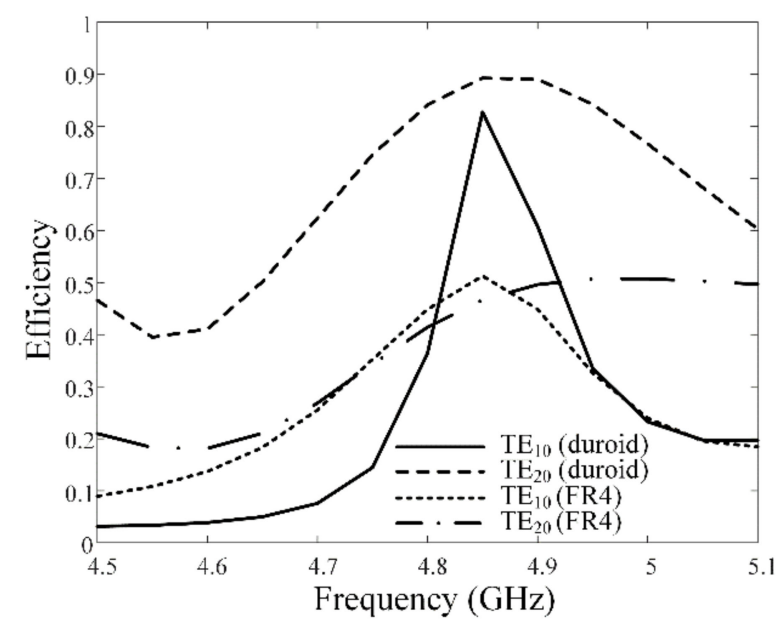

Figure 7. Efficiency comparisons by the materials of the substrate.

Figure 8 shows measured and simulated maximum gains in the upper hemisphere of the radiation patterns for the $\mathrm{TE}_{10}$ and $\mathrm{TE}_{20}$ modes according to the frequency. At $4.85 \mathrm{GHz}$, a measured maximum gain of $2.73 \mathrm{dBi}$ for the $\mathrm{TE}_{10}$ mode is observed at $\theta=0^{\circ}$, and a measured maximum gain of $-3.9 \mathrm{dBi}$ for the $\mathrm{TE}_{20}$ mode is observed at $\theta=45^{\circ}$. Figure $9 \mathrm{a}$ presents the simulated and measured $2 \mathrm{D}$ radiation patterns for the $\mathrm{TE}_{10}$ mode where $\Sigma$ is defined as the amplitude of the sum pattern in the $z x$-plane at $4.85 \mathrm{GHz}$. Similarly, Figure $9 \mathrm{~b}$ is for the $\mathrm{TE}_{20}$ mode, and $\Delta$ is defined as the amplitude of the difference pattern. The measured gains at the bore sight $\left(\theta=0^{\circ}\right)$ in the $\mathrm{TE}_{10}$ and $\mathrm{TE}_{20}$ modes are $2.73 \mathrm{dBi}$ and $-12.3 \mathrm{dBi}$, respectively, which shows a difference of more than $15 \mathrm{~dB}$. These results verify that the proposed antenna with the multi-mode SIW feeder is suitable for monopulse systems that require large gain difference between the sum and difference patterns. 


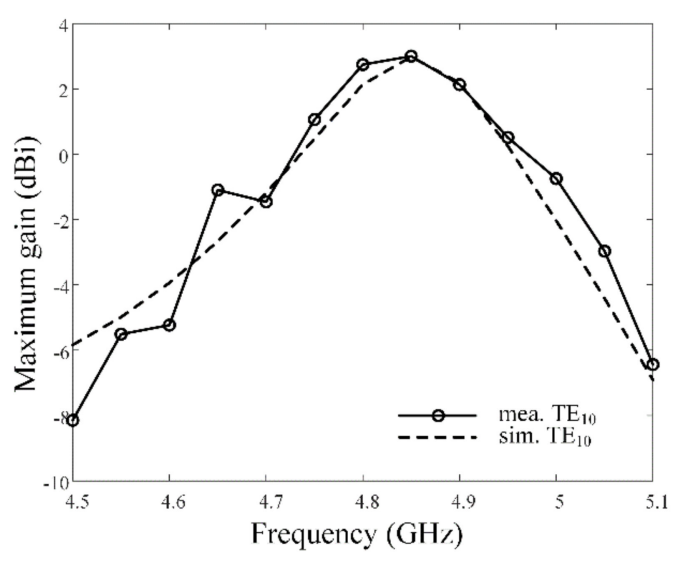

(a)

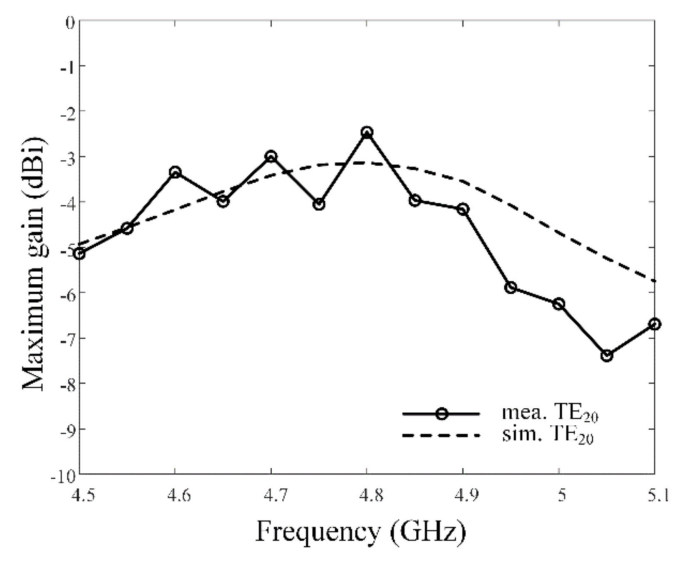

(b)

Figure 8. Simulated and measured maximum gains in the upper hemisphere of the proposed antenna: (a) $\mathrm{TE}_{10}$ mode; (b) $\mathrm{TE}_{20}$ mode.

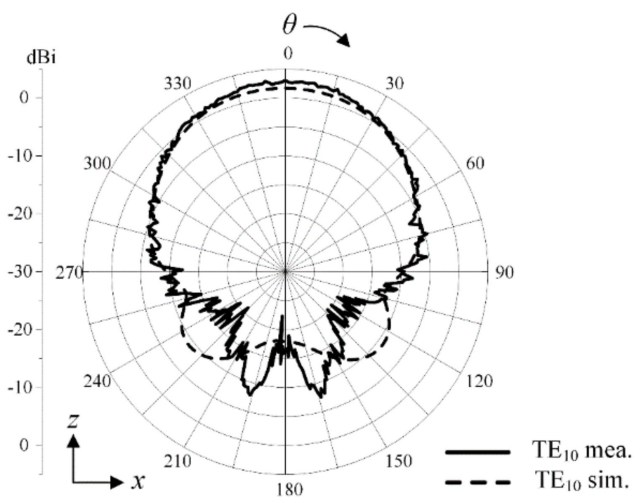

(a)

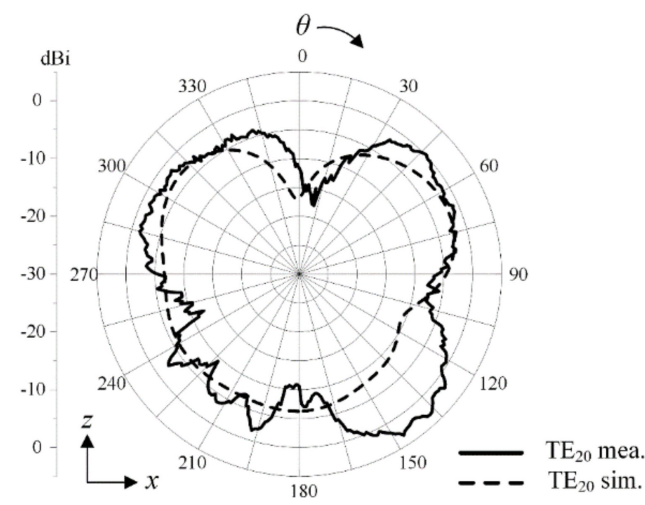

(b)

Figure 9. Two-dimensional radiation patterns of the proposed antenna: (a) TE 10 mode; (b) TE 20 mode.

\section{Antenna Analysis and DOA Estimation}

For impedance characteristic observation, we simulated input impedances for TE10 and TE20 modes, as shown in Figure 10. The resistance and reactance of the TE10 mode are $67.7 \Omega$ and $7.1 \Omega$, and for TE2 0 mode, the resistance and reactance of $51.3 \Omega$ and $15.0 \Omega$ are obtained, respectively. Figure 11a,b show the E-field distributions of the proposed antenna excited by SIWs with different modes, which are observed at $81 \times 51$ points in the $y=0 \mathrm{~mm}$ plane. Inside the SIWs, the electric-field distributions of the $\mathrm{TE}_{10}$ and $\mathrm{TE}_{20}$ modes are clearly observed, which is achieved by the structural differences of the SIWs. Each E-field with different modes in the SIWs radiates the sum and difference patterns through the single patch antenna. The multi-mode SIW feeder allows the sum and difference patterns to be radiated directly without the pattern comparator of conventional monopulse systems. As a result, the complexity of the system can be significantly decreased by reducing the number of radiators and by simplifying the waveguide pattern comparator. To examine the DOA estimation of the proposed antenna, we simulate and measure $\Delta / \Sigma$ in terms of the incident angle $\theta$, as represented in Figure 12. Solid, dashed, and dotted lines indicate the measured, simulated, and ideal results of the $\Delta / \Sigma$ values for the DOA estimation. The simulated and measured results significantly deviate from the ideal results due to the asymmetric microstrip feeding line structure in $\mathrm{TE}_{20} \mathrm{SIW}$, which causes distortions on the $\Delta$ radiation pattern. Thus, to compensate for the deviations of the DOA estimations, we derive the fitting curve $F(\theta)$ using a quadratic equation with the coefficients of $k_{1}$ and $k_{2}$, as written in Equation (1). The coefficients of $k_{1}$ and $k_{2}$ correspond to the left $(\theta<0)$ and right $(\theta \geq 0)$ 
sides of the fitting curve, and the determined values of $k_{1}$ and $k_{2}$ are 0.019 and 0.022 , respectively. A calibration function $C(\theta)$ is then defined by calculating the difference between the $\Delta / \Sigma(\theta)_{\text {ideal }}$ and $F(\theta)$ in Equation (2). Finally, the $\Delta / \Sigma(\theta)_{\mathrm{w} / \mathrm{cal}}$ of the proposed antenna with calibration can be achieved by compensating the deviation with $C(\theta)$ in order to minimize the root mean square error (RMSE) of the DOA estimations as suggested in Equation (3).

$$
\begin{gathered}
F(\theta)=\left\{\begin{array}{c}
F_{1}(\theta)=k_{1} \theta^{2}(\theta<0) \\
F_{2}(\theta)=k_{2} \theta^{2}(\theta \geq 0)
\end{array},\right. \\
C(\theta)=\Delta / \Sigma(\theta)_{\text {ideal }}-F(\theta), \\
\Delta / \Sigma(\theta)_{\mathrm{w} / \text { cal. }}=\Delta / \Sigma(\theta)_{\mathrm{w} / \mathrm{o} \mathrm{cal} .}+C(\theta) .
\end{gathered}
$$

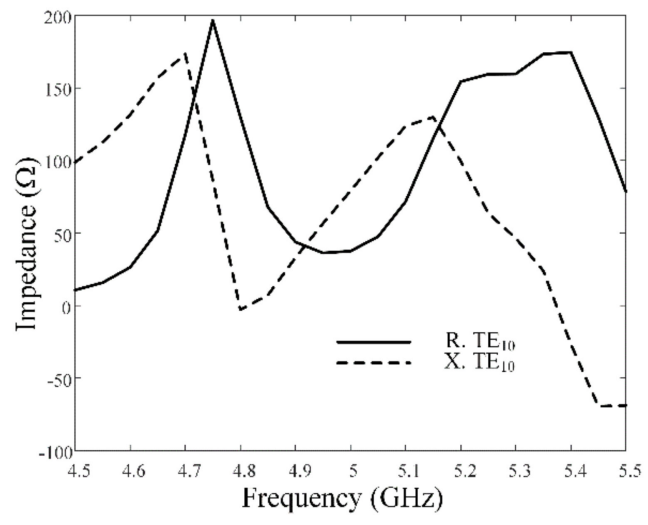

(a)

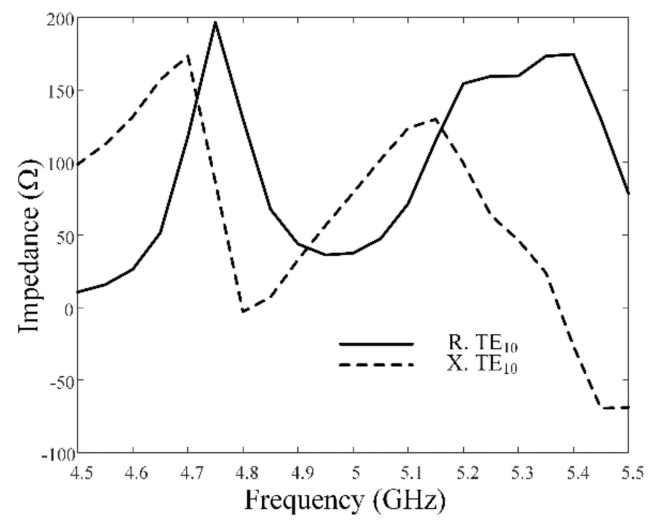

(b)

Figure 10. Input impedance of the proposed antenna: (a) $\mathrm{TE}_{10}$ mode; (b) $\mathrm{TE}_{20}$ mode.

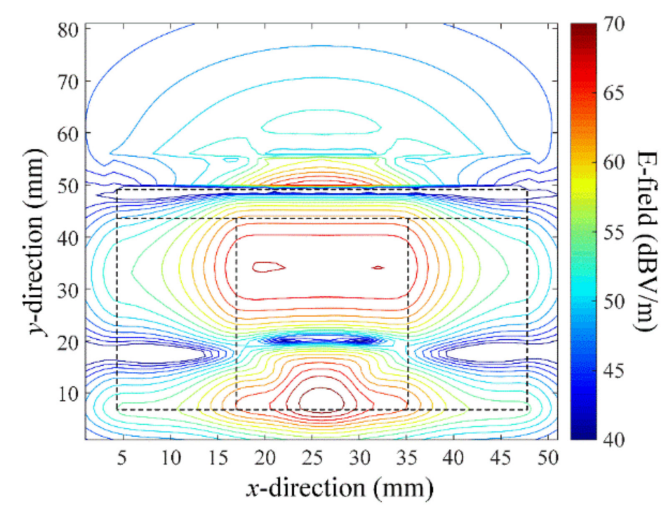

(a)

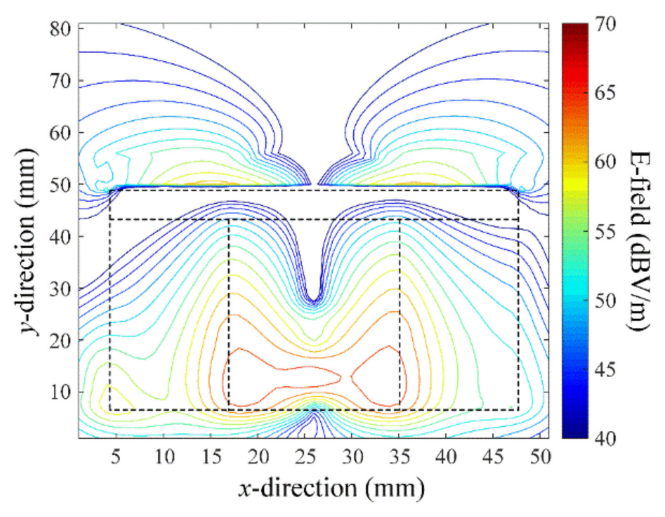

(b)

Figure 11. Near-field distributions: (a) $\mathrm{TE}_{10}$ mode; (b) $\mathrm{TE}_{20}$ mode. 


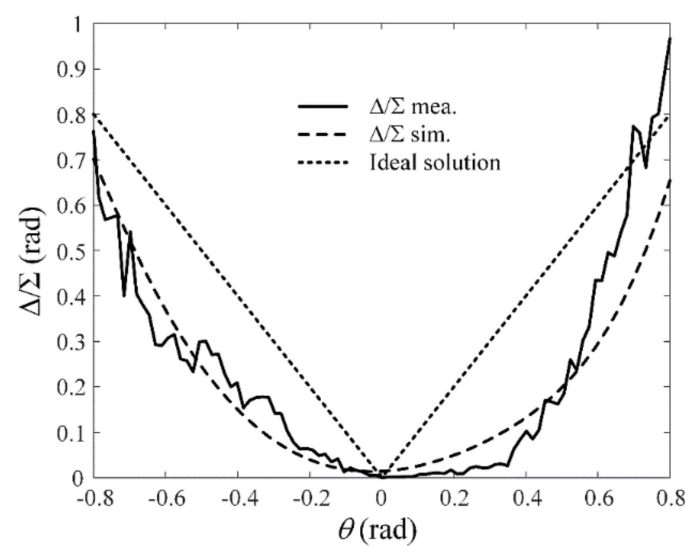

Figure 12. Simulated and measured $\Delta / \Sigma$ of the proposed antenna.

Figure 13 shows the root mean square error (RMSE) with and without the calibration for the DOA estimation according to the incident angle $\theta$. The RMSE values are averaged at incident angles between -0.5 and 0.5 . Through this calibration, the average RMSE of 0.07 is obtained, which is 0.1 lower than that of the uncalibrated result.

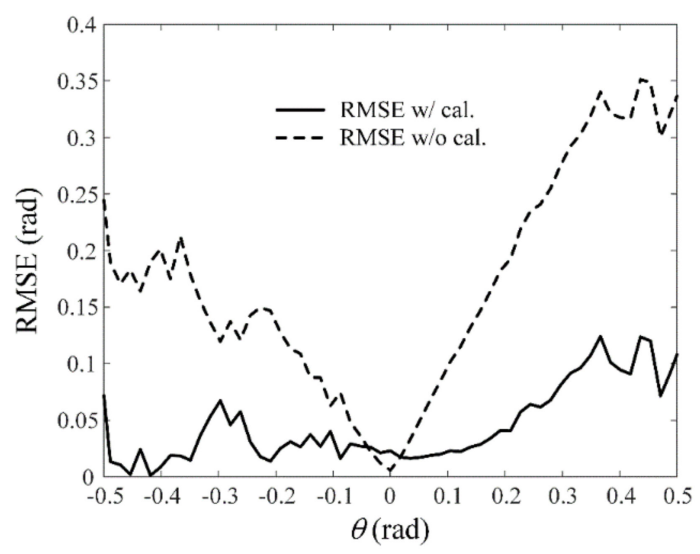

Figure 13. Root mean square error (RMSE) in terms of the incident angle $\theta$.

\section{Conclusions}

In this paper, we proposed the novel design structure of a monopulse antenna system that could operate with only a single radiator to reduce the aperture size. The complicated waveguide comparator was also replaced by the simple two-port SIW feeding network that could obtain the ratio of the sum and difference patterns. The two ports in the SIW feeding network transmitted the $\mathrm{TE}_{10}$ and $\mathrm{TE}_{20}$ modes to the single patch antenna. To verify the feasibility, the proposed antenna was fabricated, and its antenna characteristics were measured in a full anechoic chamber. The measured reflection coefficients of the SIW for both the $\mathrm{TE}_{10}$ and $\mathrm{TE}_{20}$ modes were $-18.8 \mathrm{~dB}$ and $-11.5 \mathrm{~dB}$ at $4.85 \mathrm{GHz}$. The measured and simulated mutual couplings were maintained below $-30 \mathrm{~dB}$ from $4.5 \mathrm{GHz}$ to $5.5 \mathrm{GHz}$. The maximum gains of $3.1 \mathrm{dBi}$ and $-2.2 \mathrm{dBi}$ for the $\mathrm{TE}_{10}$ mode and $\mathrm{TE}_{20}$ mode were observed at $\theta=0^{\circ}$ and $\theta=45^{\circ}$, respectively. The accuracy of the DOA estimation was further improved by applying the derived calibration function to the resulting sum and difference ratio. Through this calibration, the RMSE value of 0.07 was obtained, which was 0.1 lower than that of the uncalibrated result. For the future work, we will increase the efficiency of the proposed monopulse system using low loss material such as Duroid and Teflon that can increase the efficiency up to $82 \%$ for the proposed design based on electromagnetic (EM) simulation results. 
Author Contributions: Conceptualization, S.Y., T.H.L. and H.C.; methodology, S.Y. and T.H.L.; software, S.Y.; validation, S.Y., T.H.L. and H.C.; formal analysis, S.Y., T.H.L. and B.-j.J.; investigation, S.Y. and T.H.L.; writing-original draft preparation, S.Y. and T.H.L.; writing-review and editing, S.Y. and H.C.; visualization, S.Y.; supervision, H.C.; project administration, H.C.; funding acquisition, H.C. All authors have read and agreed to the published version of the manuscript.

Funding: This work was supported by the Samsung Research Funding Center of Samsung Electronics under project number SRFC-IT1801-06.

Conflicts of Interest: The authors declare no conflict of interest.

\section{References}

1. Ruoyu, F.; Faruk, U.; Pascal, A.; Alexandar, Y. MIMO monopulse target localisation for automotive radar. IET Radar Sonar Navig. 2018, 12, 1131-1136.

2. Yi, Z.; Houjun, S.; Xiaowen, X.; Qing, H.L. Amplitude angle monopulse estimation for the for-channel hybrid polarimetric radar system. IEEE Antennas Wirel. Propag. Lett. 2017, 16, 2889-2893.

3. Karim, T.; Mauro, E.; Laurent, L.C.; Ronan, S. SIW pillbox antenna for monopulse radar applications. IEEE Trans. Antennas Propag. 2015, 63, 3918-3927.

4. Laheurte, J.M. Uniplanar monopulse antenna based on odd/even mode excitation of coplanar line. Electron. Lett. 2001, 37, 338-340. [CrossRef]

5. Hojoo, L.; Jaesik, K.; Jaehoon, C. A compact Rx antenna Integration for 3D direction-finding passive radar. J. Electromagn. Eng. Sci. 2019, 19, 188-196.

6. Hofstetter, E.; Delong, D. Detection and parameter estimation in an amplitude-comparison monopulse radar. IEEE Trans. Inf. Theory 1969, 15, 22-30. [CrossRef]

7. Edoardo, M. Angle estimation in amplitude comparison monopulse systems. IEEE Trans. Aerosp. Electron. Syst. 1969, 5, 205-212.

8. Subbarao, B.; Fusco, V.F. Single aperture monopulse horn antenna. IEEE Microw. Wirel. Compon. Lett. 2005, 15, 80-82. [CrossRef]

9. Lee, K.M.; Chu, R.S. Design and analysis of a multimode feed horn for a monopulse feed. IEEE Trans. Antennas Propag. 1988, 36, 171-181. [CrossRef]

10. Hannan, P.; Loth, P. A monopulse antenna having independent optimization of the sum and difference modes. IRE Int. Conv. Rec. 1961, 1, 57-60.

11. Zhong, W.Y.; Guang, M.W.; Chen, X.Z. Broadband planar monopulse antenna array of C band. IEEE Antennas Wirel. Propag. Lett. 2009, 8, 1325-1328. [CrossRef]

12. Paolo, R.; Andrea, F.M. Optimal synthesis of reconfigurable planar arrays with simplified architectures for monopulse radar applications. IEEE Trans. Antennas Propag. 2015, 63, 1048-1058.

13. Sung, J.Y.; Jaehoon, C. A low-profile broadband array antenna for home repeater application. J. Electromagn. Eng. Sci. 2018, 18, 261-266.

14. Puneeth, K.T.; Karthik, R.; Krishnamoorthy, K. A wideband circularly polarized slot antenna backed by a frequency selective surface. J. Electromagn. Eng. Sci. 2019, 19, 166-171.

15. Hao, W.; Da, G.F.; Chen, X.G. A compact single layer monopulse microstrip antenna array. IEEE Trans. Antennas Propag. 2006, 54, 503-509.

16. Fei, Y.; Yonjun, X.; Lihua, Z. Single patch antenna with monopulse patterns. IEEE Microw. Wirel. Compon. Lett. 2016, 26, 762-764.

17. Sang, G.K.; Kai, C. Low-cost monopulse antenna using Bi-directionally-fed microstrip patch array. Electron. Lett. 2003, 39, 1428-1429.

18. Xiong, Z.; Chuang, M.T.; Jun, S.B.; Wei, J.P. SIW-fed Yagi antenna and its application on monopulse antenna. IEEE Antennas Wirel. Propag. Lett. 2014, 13, 1035-1308.

19. Bing, L.; Wei, H.; Zhenqi, K.; Xiaoxin, Y.; Guoqing, L.; Jixin, C.; Hongjun, T.; Ke, W. Substrate integrated waveguide (SIW) monopulse slot antenna array. IEEE Trans. Antennas Propag. 2009, 57, 275-279.

20. Javad, A.; Zahra, A. A novel compact monopulse parallel plate slot array antenna. IEEE Antennas Wirel. Propag. Lett. 2015, 15, 762-765.

21. Kian, S.A.; Leong, Y.C.; Chee, H.L. A wide-band monopulse comparator with complete nulling in all delta channels throughout sum channel bandwidth. IEEE Trans. Microw. Theory Tech. 2003, 51, 371-373. [CrossRef] 
22. Uysal, S.; Seow, A.C. An X-band microstrip compact monopulse processor. IEEE Microw. Conf. Asia Pac. 1999, 2, 21-24.

23. Yi, L.; Hu, Y.; Yan, H.; Jiang, Z. Compact monopulse sum-difference comparator based on double-layer substrate integrated waveguide. Electron. Lett. 2017, 53, 1477-1479.

24. Haidong, C.; Wenquan, C.; Qingqiang, H.; Wenjie, F.; Xu, W.; Ke, W. Compact substrate integrated waveguide (SIW) monopulse network for Ku band tracking system applications. IEEE Trans. Microw. Theory Tech. 2014, 62, 472-480.

25. Teng, L.; Wenbin, D.; Hongfu, M. A monopulse slot array antenna based on dual-layer substrate integrated waveguide (SIW). In Proceedings of the 2016 IEEE 5th Asia-Pacific Conference on Antennas Propagation, Kaohsiung, Taiwan, 26-29 July 2006; IEEE: Piscataway, NJ, USA, 2016; pp. 373-374.

26. Jose, L.G.T.; David, C.R.; Jose, A.L.P.; Alejandro, S.M.S. Hybrid analog-digital processing system for amplitude-monopulse RSSI-based MiMo WiFi Direction-of-arrival estimation. IEEE J. Sel. Top. Signal Process. 2018, 12, 529-540.

27. Vikram, V.M.; Sha, S.; Bredow, J.W.; Lu, M. Wideband cavity backed slot antenna for automotive monopulse radars. Electron. Lett. 2010, 46,1-2. [CrossRef]

28. You, S.W.; Chung, H.K.; Sang, G.L. Range resolution improvement of a $24 \mathrm{GHz}$ ISM band pulse radar-A feasibility study. IEEE Sens. J. 2015, 15, 7142-7149.

29. Lei, Z.; Mengdao, X.; Cheng, W.Q.; Jun, L.; Zheng, B. Achieving higher resolution ISAR imaging with limited pulses via compressed sampling. IEEE Geosci. Remote Sens. Lett. 2009, 6, 567-571.

30. Xin, Z.; Peter, K.; Yaakov, B. Monopulse radar detection and localization of multiple unresolved targets via joint bin processing. IEEE Trans. Signal Process. 2005, 53, 1225-1236.

31. Jianfeng, Z.; Shaowei, L.; Shufang, L.; Quan, X. 60 GHz substrate-integrated waveguide-based monopulse slot antenna arrays. IEEE Trans. Antennas Propag. 2018, 66, 4860-4865.

32. Feng, X.; Ke, W. Guided-Wave and Leakage Characteristics of Substrate Integrated Waveguide. IEEE Trans. Microw. Theory Tech. 2005, 53, 66-73. [CrossRef]

33. Peng, W.; Jirong, L.; Quan, X. Wideband excitation technology of TE20 mode substrate integrated waveguide (SIW) and its applications. IEEE Trans. Microw. Theory Tech. 2015, 63, 1863-1874.

34. Yan, D.; Ke, W. Substrate integrated waveguide-to-microstrip transition in multilayer substrate. IEEE Trans. Microw. Theory Tech. 2007, 55, 2839-2844.

35. Xiaobo, H.; Ke, W. A broadband U-slot coupled microstrip-to-waveguide transition. IEEE Trans. Microw. Theory Tech. 2012, 60, 1210-1217.

36. Ali, F.; Thomas, E.R.; Mohammad, T.G.; Reza, Z. Aperture-coupled microstrip patch antenna fed by orthogonal SIW line for millimetre-wave imaging applications. IET Microw. Antennas Propag. 2017, 11, 811-817.

37. Jingxuan, W.; Yi, X.Z.; Yong, C.J.; Chi,Z. Design of broadband dual-polarized array based on three-dimensional SIW feeding for 5G millimeter-wave applications. In Proceedings of the 2019 International Symposium on Antennas and Propagation (ISAP), Xi'an, China, 27-30 October 2019; IEEE: Piscataway, NJ, USA, 2019; Volume 1, pp. 1-3.

38. Bassel, Y.; El, K.; Tarek, D.; Ke, W. Substrate-integrated waveguide vertical interconnects for 3-D integrated circuits. IEEE Trans. Compon. Pack. Manuf. Technol. 2012, 1, 1526-1535.

Publisher's Note: MDPI stays neutral with regard to jurisdictional claims in published maps and institutional affiliations.

(C) 2020 by the authors. Licensee MDPI, Basel, Switzerland. This article is an open access article distributed under the terms and conditions of the Creative Commons Attribution (CC BY) license (http://creativecommons.org/licenses/by/4.0/). 